\title{
A high cervical intradural extramedullary bronchogenic cyst. Case report
}

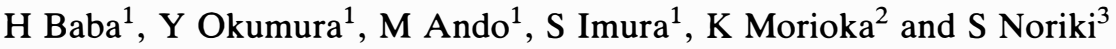 \\ ${ }^{1}$ Department of Orthopaedic Surgery, ${ }^{2}$ The Second Department of Surgery, ${ }^{3}$ The First Department of Pathology, \\ Fukui Medical School, Shimoaizuki 23, Matsuoka, Fukui 910-11, Japan
}

\begin{abstract}
This article describes a 16-year-old male patient, otherwise healthy, with intractable suboccipital pain due to an intradural, extramedullary bronchogenic cyst at $\mathrm{C} 1$ level. Computed tomographic and magnetic resonance imaging scans showed an extramedullary cystic lesion on the right anterolateral side of the spinal cord at $\mathrm{C} 1$ level. No other vertebral, spinal cord, or cutaneous abnormality was associated. The patient underwent posterolateral resection of the $\mathrm{C} 1$ bony ring on the right side, followed by complete removal of a cyst microsurgically. Histology suggested that the mass, with its contents of slightly viscous and opaque liquid, was an atypical form of bronchogenic cyst with abundant pseudostratified ciliated epithelial cells.
\end{abstract}

Keywords: bronchogenic cyst; craniovertebral junction; extramedullary tumour

\section{Introduction}

A variety of tumour/tumourous lesions occurs in the spine, and the craniocervical junctional area is a site in which many anomalies can be associated with a complex neural and vertebral malformation. There is a $<3 \%$ incidence of cyst in all spinal cord tumours and tumourous lesions. A bronchogenic cyst, being relatively common in the posterior mediastinum of a child ${ }^{1-3}$ is extremely rare intrathecally. ${ }^{4}$ The authors describe a case with an atypical type of bronchogenic cyst in the upper cervical spine.

\section{Case report}

The patient, a 16-year-old boy, first experienced pain in the posterior upper neck region in April 1992. He was the product of a healthy pregnancy and normal parturition, and his growth was healthy. On February 201993 he experienced intractable neck pain at the suboccipital area, predominantly on the right side, and a pulsatile headache, and was admitted for further examination on March 161993. On admission, physical, neurological and otolaryngological findings were unremarkable. Movement of the neck was slightly restricted due to pain in the suboccipital region. Plain cervical films were normal except for a slightly widened posterior interlaminar space between $\mathrm{C} 1$ and $\mathrm{C} 2$. Myelography and computed tomographic myelography showed a clearly delineated intradural, extramedullary tumour at $\mathrm{C} 1$ level, located anterolateral to the spinal cord on the right (Figure 1). The cerebrospinal fluid was normal. The tumour appeared to be independent of the spinal cord which was considered to be normal in size and in configuration.

Magnetic resonance imaging (MRI) scans demonstrated an extramedullary mass of intermediate signal intensity on the T1-weighted image (Figure 2a,b) and slightly high

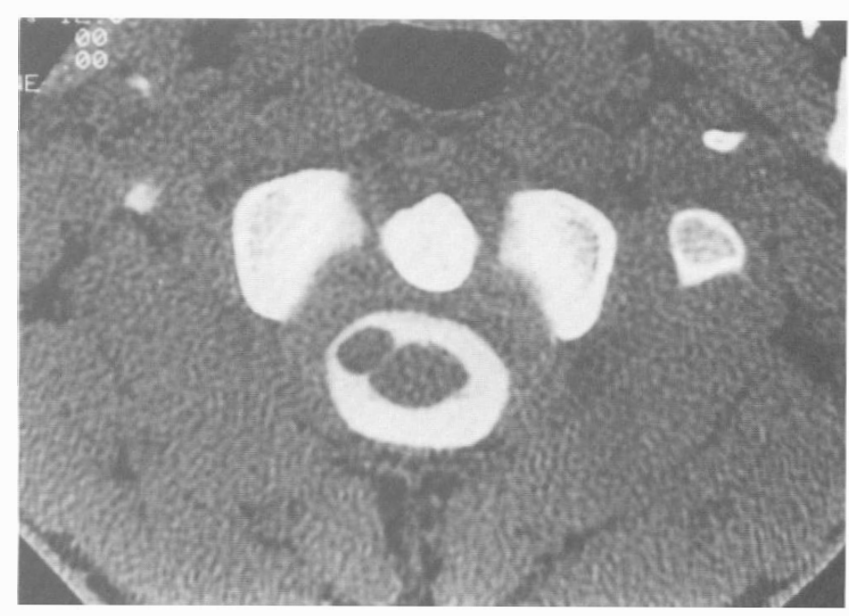

Figure 1 Computed tomographic myelography at the $\mathrm{C} 1$ level showing an extramedullary mass lesion anterolateral to the spinal cord

signals in T2 (Figure 2c), suggesting a cystic lesion containing fluid. No other soft tissue or vertebral abnormality was revealed by MRI and CT scans.

On April 151993 the patient was operated on through a right-side posterolateral oblique approach to the $\mathrm{C} 1$ vertebra. A limited posterior exposure of the $\mathrm{C} 1$ and $\mathrm{C} 2$ vertebrae on the right side only was followed by partial resection of the arch of the $\mathrm{C} 1$ vertebra posterolaterally. Neither craniotomy nor laminotomy of $\mathrm{C} 2$ were necessary. The vertebral artery on the right was visualised and was protected laterally with a Caspar retractor. The longus capitis minor muscles attached to $\mathrm{C} 1$ and the major to $\mathrm{C} 2$ were identified and were preserved to prevent future spinal instability. A $2 \mathrm{~cm}$ posterolateral longitudinal opening was made in the dura and the arachnoid. 
a
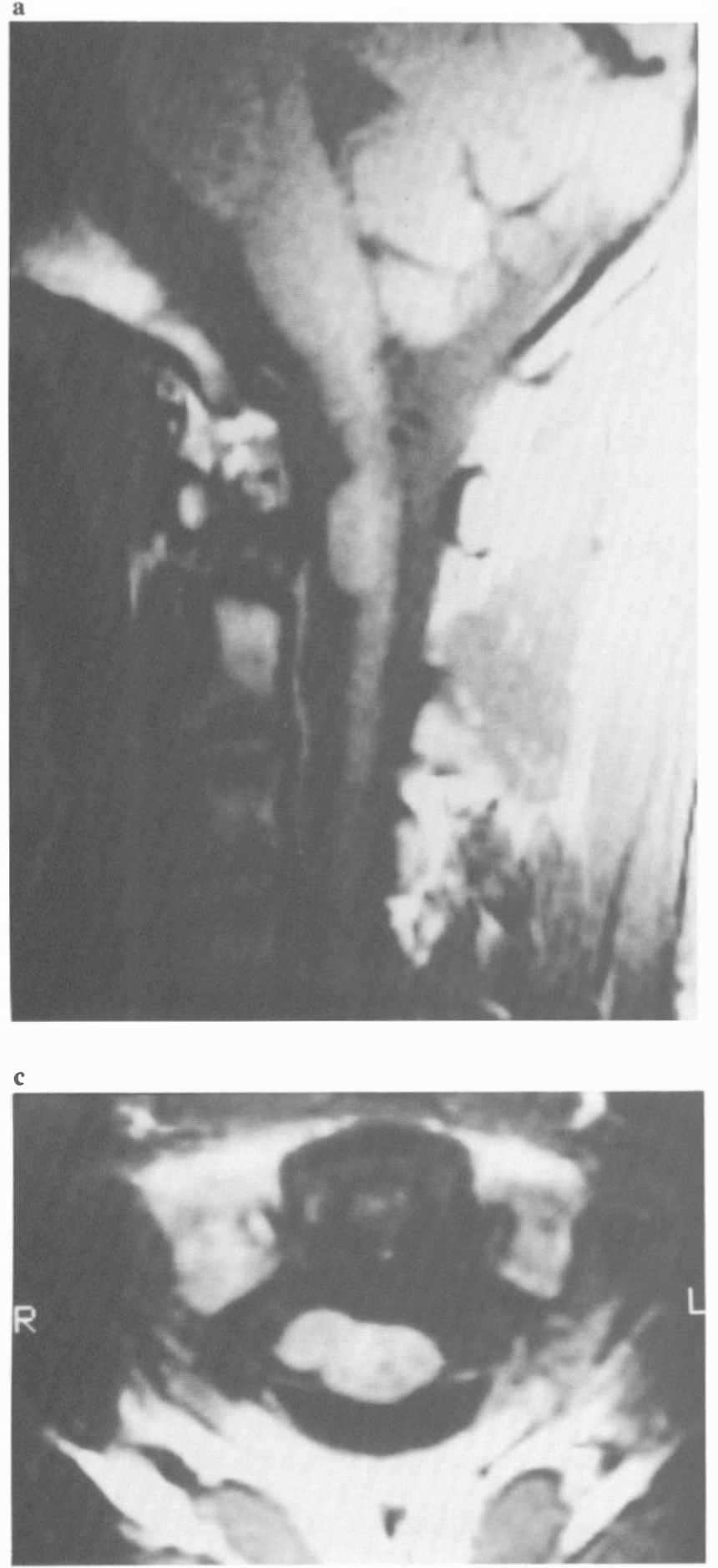

The cerebrospinal fluid was clear, with normal cell count and chemistry. The mass, yellow-brown in colour, shining and semitransparent, was cystic and was located between the posterior spinal rami of $\mathrm{C} 1$ and $\mathrm{C} 2$, displacing the spinal cord to the left and dorsally (Figure 3a). The cyst appeared to have no connection to spinal branches of the accessory nerves or to the $\mathrm{C} 1$ and $\mathrm{C} 2$ nerve roots. With the aid of an operating microscope the cystic lesion was totally removed after reducing its size by suction of the contents (Figure $3 b$ ); these were slightly opaque, and the fluid was consistent with cerebrospinal fluid regarding the biochemical findings.

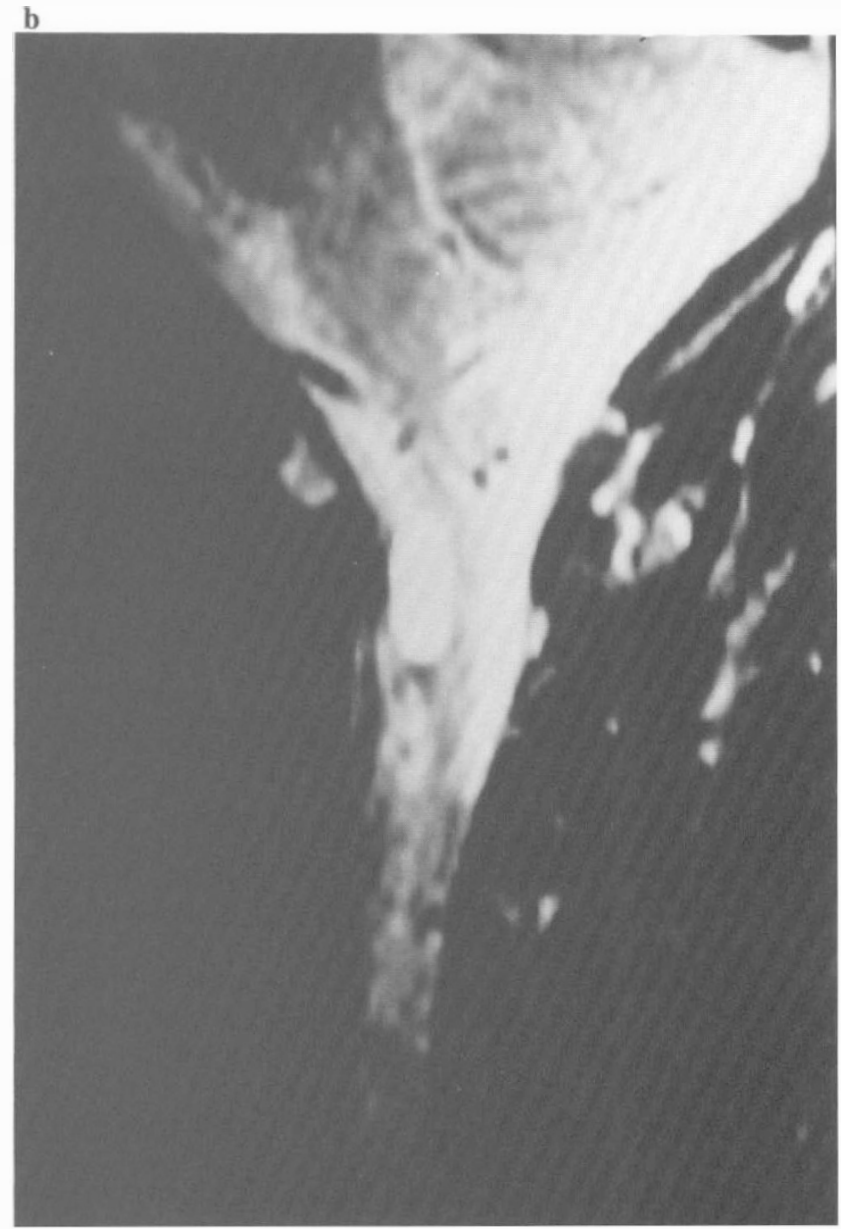

Figure 2 Magnetic resonance imaging of the case. (a) Relatively sharp delineated lesion appears to displace the spinal cord dorsally in a T1-weighted MRI in an sagittal image (TR $600 \mathrm{~ms}$, TE40 ms, spin-echo imaging). (b) Spin-echo preoperative MRI: T1-weighted images (TR $600 \mathrm{~ms}$, TE $20 \mathrm{~ms}$ ). (c) Spin-echo preoperative MRI: T2-weighted images (TR $2000 \mathrm{~ms}$, TE $120 \mathrm{~ms}$ ). The lesion showing signal intensities equivalent to cerebrospinal fluid in a T2weighted MRI

Histologically, the inner surface of the cyst wall was lined by a single-layer, pseudostratified or stratified cuboidal to columnar epithelial cells with abundant cilia (Figure 4a, b); the specimen was considered to be a bronchogenic cyst. The outer aspect of the cyst had no lining cells. Some substituting cells were observed but goblet cells were not apparent in the pits of the epithelium. Within the subepithelial stroma there were no typical bronchial tissue components such as hyaline cartilage, mucous glands, smooth muscle, or nerve bundles. These histological findings suggested that the diagnosis was an atypical type of bronchogenic cyst. 
a

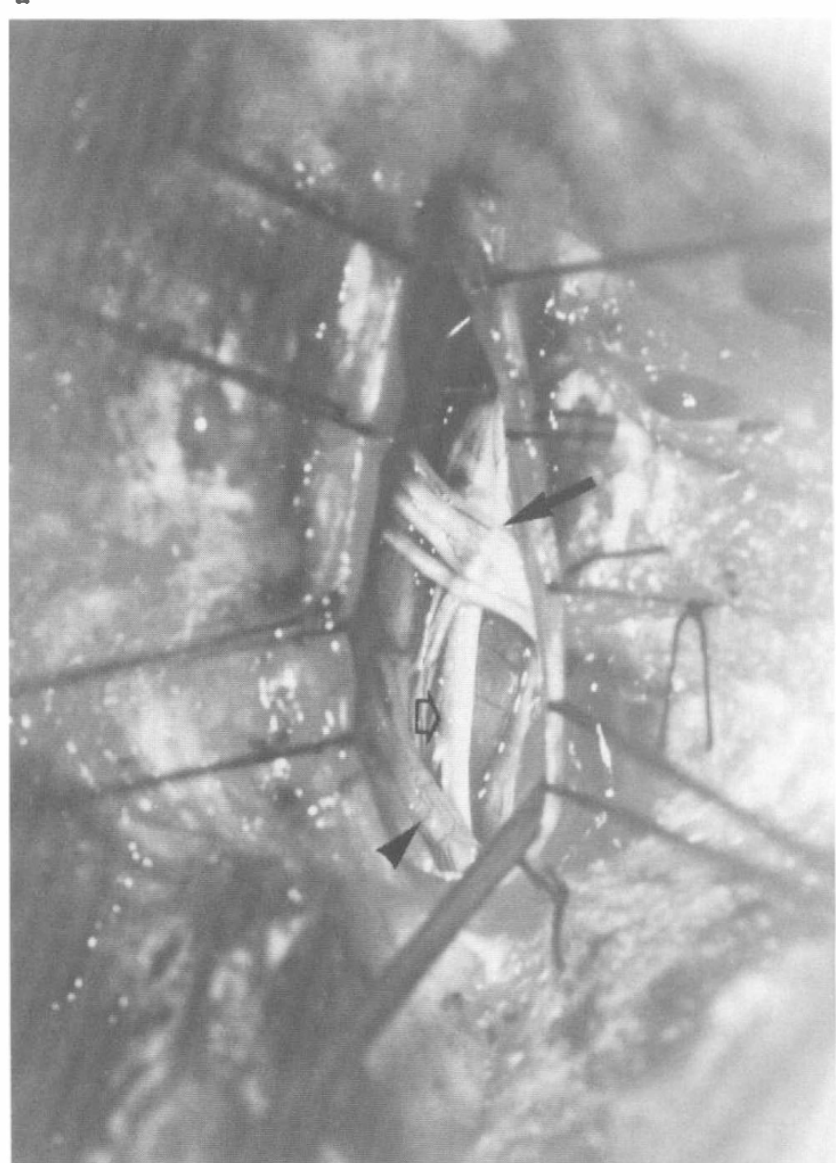

b

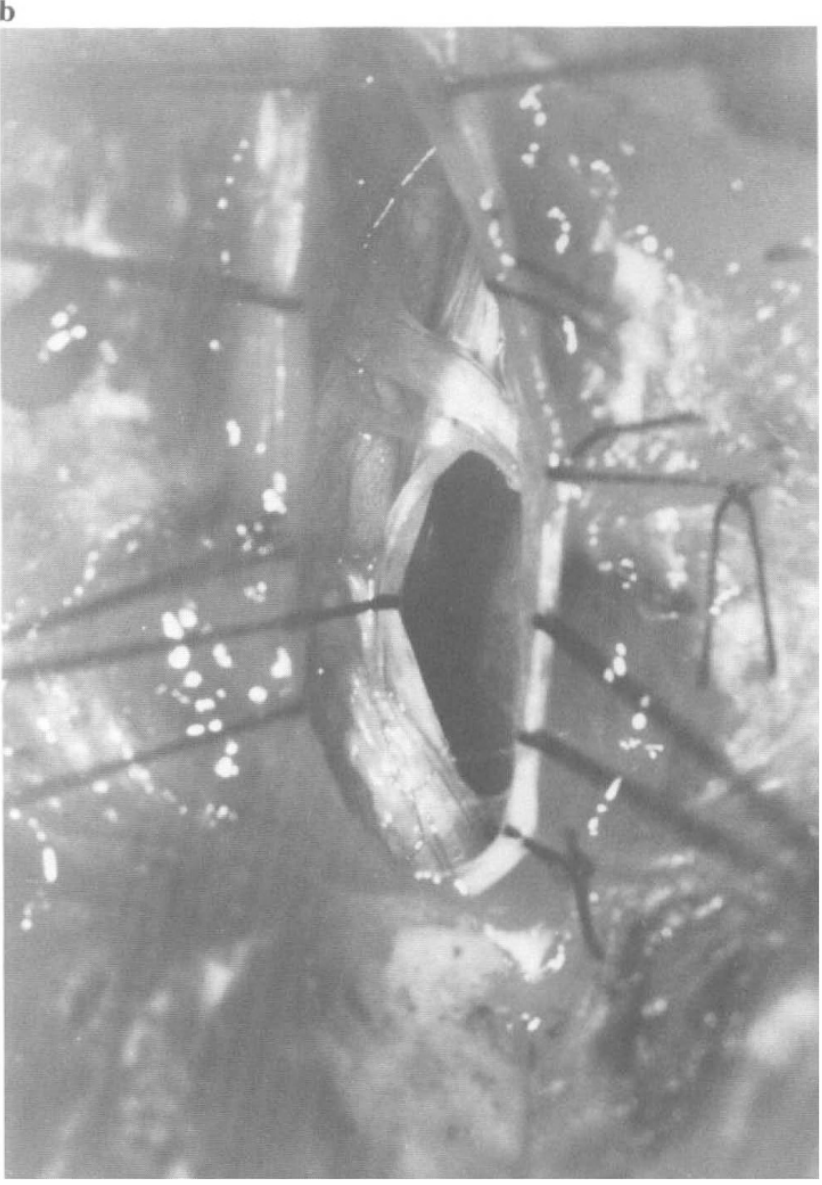

Figure 3 Intraoperative photographs showing the cyst located anterolaterally to the spinal cord. (a) The cyst developed dorsally to between $\mathrm{C} 1$ (arrow) and C2 (arrow head). The spinal branch of the accessory nerve (open arrow). (b) The cyst was completely extirpated

The postopertive course was unremarkable and suboccipital pain completely resolved. An MRI scan 12 months after surgery showed that the spinal cord was normal, (Figure 5), and the patient was in good health without any symptoms.

\section{Discussion}

A spinal bronchogenic cyst is very rare.$^{5}$ Histologically, the cyst contains respiratory tissue organoids. It is considered a congenitally aberrant or remnant malformation but is distinguished from other cystic or tumourous lesions such as a dermoid/epidermoid, neurenteric (enterogenous), arachnoidal or ependymal cyst. Of these, a neurenteric cyst being a complex congenital malformation ${ }^{6-10}$ is to be differentiated histologically.

Macdonald $e l$ al ${ }^{11}$ described transient anomalous adhesions or enteric remnants between the primitive neuroectoderm and endoderm through a split notochord in the third week of embryonic life, resulting in the formation of a neurenteric cyst. Mann et al ${ }^{12}$ suggested a combination of anterior and posterior vertebral anomalies with a fistulous track dorsally, and hence concluded that a neurenteric cyst should be considered to be part of a split notochord condition, as described by Bentley and Smith. ${ }^{13}$ Most of the literature maintains that a neurenteric cyst is an embryonic malformaion. ${ }^{14}$

Wilkinson et $a l^{15}$ have reported another type of intraspinal cyst, possibly congenital, with organ specificity to respiratory tissue. They observed that the cyst wall had ciliated pseudostratified epithelium with the organoid structure of a bronchus, with a lamina propria, smooth muscle, glands and nerve bundle. Most reported examples of neurenteric cysts have shown some features of gastrointestinal organ specificity. Ho and Tiel ${ }^{16}$ and Wilkinson et al ${ }^{15}$ concluded that a cyst is bronchogenic if it has the features of respiratory tissue structure. Wilkins and $\mathrm{Odom}^{17} \mathrm{di}-$ vided intrathecal cysts into three histological categories: category $\mathrm{A}$, a simple cyst lined by epithelium on a basement membrane with a thin wall of connective tissue; category B, a cyst lined by epithelium with a wall containing tissues found along the gastrointestinal or tracheobronchial tree; and category C, like B but with ependymal and glial tissues as an intrinsic part of the lesion. In category B, alimentary and bronchial tissues were distinguished. Our patient described here showed histological features suggesting a bronchogenic cyst, especially concerning the inner wall of the cyst, but with a lack of respiratory organ specificity in the 
$\mathbf{a}$

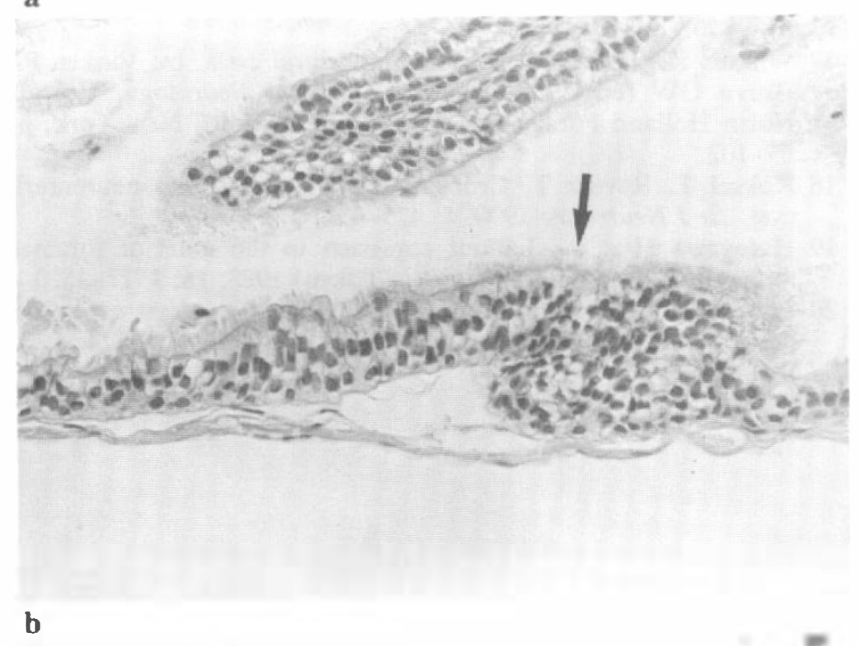

b

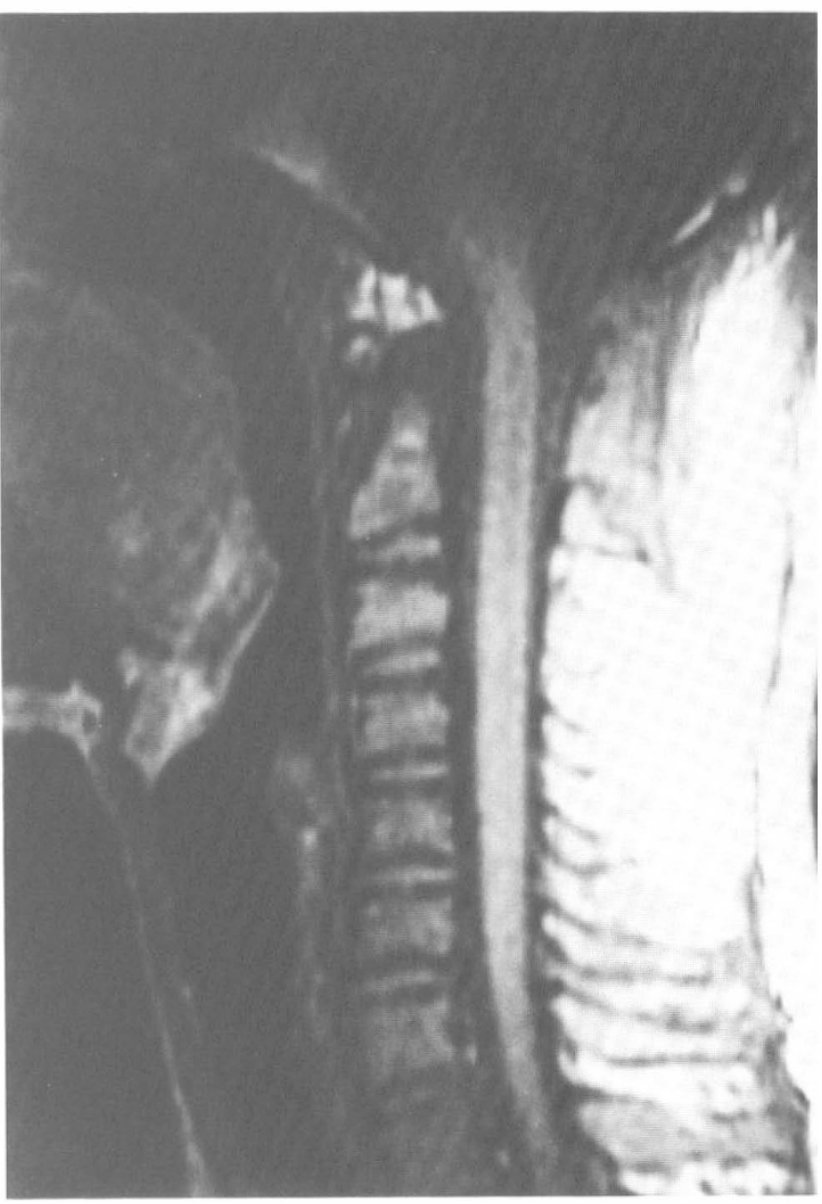

Figure 5 Spin-echo MRI taken 12 months following surgery: T1-weighted (TR $600 \mathrm{~ms}$, TE $20 \mathrm{~ms}$ ) with a bronchogenic cyst (hematoxylin and eosin stain). (a) The inner wall (arrow) of the cyst consisting of pseudostratified or stratified ciliated epithelium, while the outer wall shows only connective tissue (magnification $\times 50$ ). (b) Ciliated epithelium resembles tracheobronchial tissue (magnification $\times 100$ )

stroma. A close histological similarity to the cases presented by Yamashita et al, Ho and Tiel, and Wilkinson et al suggests that the current cyst is bronchogenic and therefore may be classified as a category A type of lesion. Concerning the surgical treatment, special attention was paid to avoiding major structural compromise: to preserve the neck and head extensor muscles as far as possible, and to minimize the area of bone resection and durotomy by using a microsurgical technique. A cyst located at the craniovertebral junction is removed by means of a transoral, ${ }^{18}$ lateral $^{19}$ or posterior approach. ${ }^{20} \mathrm{~A}$ mass lesion displaced lateral to the spinal cord at $\mathrm{C} 1$ can be removed through a posterolateral oblique approach with an appropriate view of the lesion. The minimally accessed posterolateral approach is recommeded for removal of a cyst with preservation of cervical spine stability.

\section{References}

1 Bier R, Ethier S. Congenital bronchogenic cyst. J Can Assoc Radiol 1978; 29: 69-70.
2 Swarnaker M, Behera D, Suri RK, Malik SK. Congenital bronchial cyst. Indian J Chest Dis Allied Sci 1989; 31: 279-282.

3 Uyama T, Monden Y, Sumitomo, Miura K, Kinura S. Carcinoembryonic antigen and serum carbohydrate antigen 19-9 in benign pulmonary or mediastinal cystic lesions. J Surg Oncol 1989; 41: 103-108.

4 Duthel R, Brunon J, Michel D, Boucheron S. Kyste bronchogenique intramedullaire. A propos d'un cas. Discussion du syndrome d'adhesion endo-ectodermique. Neurochirurgie (Paris) 1983; 29: 155-160.

5 Yamashita J, Maloney AFJ, Harris P. Intradural spinal bronchogenic cyst: case report. J Neurosurg 1973; 39: 240-245.

6 Arai Y et al. Spinal neurenteric cyst. Spine 1992; 17: 1421-1424.

7 LeDoux MS et al. Lumbosacral neurenteric cyst in an infant. J Neurosurg 1993; 78: 821-825.

8 Lerma $\mathrm{S}$ et al. Intradural neurenteric cyst. Neurochirurgia (Stuttg) 1985; 28: 228-23.

9 Rivierez $\mathbf{M}$ et al. Kyste neuro-enterique intramedullaire sans malformation associee. Un cas. Neurochirurgie (Paris) 1989; 35: 191-195.

10 Schmidbauer $\mathbf{M}$ et al. Atypical vertebral artery in a patient with an intra- and extraspinal cervical neurenteric cyst. Acta Neurochir (Wien) 1991; 109: 150-153.

11 Macdonald RL, Schwarz ML, Lewis AJ. Neurenteric cyst located dorsal to the cervical spine: case report. Neurosurgery 1991; 28: 583-587.

12 Mann KS, Kholsa VK, Gulati DR, Malik AK. Spinal neurenteric cyst. Association with vertebral anomalies, diastematomyelia, dorsal fistula, and lipoma. Surg Neurol 1984; 21 : 
$358-362$.

13 Bentley JFR, Smith JR. Developmental posterior enteric remnants and spinal malformation. The split notochord syndrome. Arch Dis Child 1960; 35: 76-86.

14 Matsushima T, Fukui M, Egami H. Epithelial cells in a socalled intraspinal neurenteric cyst: a light and electron microscopic study. Surg Neurol 1985; 24: 656-660.

15 Wilkinson $\mathrm{N}$, Reid $\mathrm{H}$, Hughes $\mathrm{D}$. Intradural bronchogenic cysts. J Clin Pathol 1992; 45: 1032-1033.

16 Ho KL, Tiel R. Intraspinal bronchogenic cyst: ultrastructural study of the lining epithelium. Acta Neuropathol 1989; 78:
$513-520$

17 Wilkins RH, Odom GL. Spinal intradural cysts. In: Vinken PJ, Bruyn GW (eds). Handbook of Clinical Neurology. Vol 20 North Holland Publishing: Amsterdam, Oxford, New York, pp 55-102.

18 Koksel T, Revesz T, Crockard HA. Craniospinal neurenteric cyst. Br J Neurosurg 1990; 4: 425-428.

19 Hasegawa $\mathrm{H}$ et al. Lateral approach to the anterior foramen magnum tumor. No- Sinkeigeka (Tokyo) 1988; 16: 1517-1520.

20 Lee WY, Tseng HM, Chuang SM. Neurenteric cyst at craniocervical junction. J Formos Med Assoc 1992; 91: 722-724. 